\title{
Small Signal Stability Analysis of Multi-Area Power System
}

\author{
Sumit Kumar
}

\begin{abstract}
This paper focuses on methodologies for calculation and examination of oscillatory security of interconnected power system network against constant disturbances. For instance, voltage soundness, transient dependability and oscillatory behaviors are also the measure of power system stability, which must be evaluated. For that proposed strategies based on proportional integral and fuzzy logic controlling techniques are implemented. The integral controller-based technique provides the zero steady-state error and with adequate damping, time to reach steady state can be reduced, on the cost of oscillation in frequency and tie-line power. On the contrary, fuzzy logic has demonstrated that strategies of computational intelligence can alleviate the quick appraisal of oscillatory solidness with less time to reach steady state. Furthermore, Eigenvalues are constructed for small signal stability analysis, utilizing a parallel variation of Arnoldi technique, reducing the time essential for calculation of vast Multi-Area power frameworks. For exhibit purposes, models have been composed utilizing MATLAB/SIMULINK and with the assistance of the fuzzy logic.
\end{abstract}

Keywords: Eigenvalues, Proportional Integral (PI), Fuzzy Logic(FL), Transmission System Operator (TSO).

\section{INTRODUCTION}

Control frameworks of the multiarea system are consistently developing with even bigger limits of power and voltage[1]. Present day control frameworks are of a huge size, extending over a wide area of interconnected systems with various divisions and generating stations. With the ever-growing demand for electricity in every part of the world, power grid and power pools are inevitable. Multi-Area power system architecture is more favourable for the deregulated power industry and distributed generation. With the enormous growth of power system, congestion of the power transportation corridors remains as a challenge, the transmission system operator (TSO) might be forced to put up serious measures so as to reduce the thermal limit capacities as a result of this overloading of the power transmission corridors. Here, a three-area power system is simulated with Proportional Integral (PI) and Fuzzy Logic (FL) control scheme to enhance the reliability and stability of power system. The proposed model consists of two thermal generators and one gas turbine system for power generation which is having a much faster response. Transients due to constant load change, about 2 to $5 \%$ of total load in step form, are imposed [12].

Revised Manuscript Received on April 02, 2020

Sumit Kumar*, Scholar, OITM ( GJUS\&T HISAR), Jind (Haryana), India.

(C) The Authors. Published by Blue Eyes Intelligence Engineering and Sciences Publication (BEIESP). This is an open access article under the CC BY-NC-ND license (http://creativecommons.org/licenses/by-nc$\underline{\mathrm{nd} / 4.0 /)}$
The response of gas turbine and the thermal system will be different for the implemented load variation, as the governor time response is different in both types of systems. Our interest is to curb the frequency oscillations happening due to simulated disturbances, from the nominal frequency [3]-[4]. This is to maintain the power system stability and adequate tie-line power flow to avoid over and under loading of transmission lines. PI controlling technique is used for eliminating the frequency deviation and maintaining the steady state error to zero, likewise limiting the tie-line power variation [8]. Systems response dependent on damping factor, eventually, controls the time response of each area to reach a stable state. On the other hand, fuzzy control strategy has proven itself as a better controlling strategy in terms of reaching steady state and maintaining the stability of the system. Small signal stability analysis based on the eigenvalue is also accomplished in this paper keeping the response of thermal and gas turbine system in mind. More negative eigenvalues would be, system stability will be more which is shown in eigenvalue comparisons of the system without a controller and with PI and FL controller [5]

\section{DESIGN AND DEVELOPMENT OF PROPOSED MODEL}

\section{A. Three Area System}

Power pool frameworks interconnected together as utilities would fundamentally work freely inside their own limits and also satisfying the trades of energy by tie-lines in between areas to avoid violation in the transmission network. It is necessary to maintain the planned exchanges of tie-line control and absorption of load change by every zone to lessen the frequency deviations. In the three-area power system simulated here, each area is having its governor and turbine system [9]. With every load variation, governor's flywheel mechanism changes its speed and steam input variation will eventually change the turbine speed. Several controlling strategies have been proposed and implemented. The vital regulator having the capability of bringing down the frequency deviation to its minimum value can be placed within the auxiliary circle [7]. By using the PI controller, the power system is more likely to remain stable, with the fast-acting controller strategy. By selecting appropriate values of proportional and integral gain the oscillatory nature of the first swing can be managed to add further stability to the system. The same system is further simulated with Fuzzy controller and strategies of computational intelligence have shown better results in terms of oscillatory nature and time to reach steady state. Three territory intertwined frameworks would, in this case, be comprised of three power pools which are merged together [14]-[15].

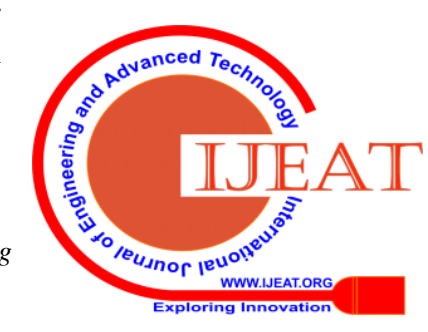




\section{Small Signal Stability Analysis of Multi-Area Power System}

A number of transmission interconnectors for power flow regulation would be arranged in form of streams and having the ability to make adjustments to the power requirement because of the interconnection made between the control territories [19].

\section{B. Fuzzy Deduction As Applied To Load Frequency Model}

The fuzzy derivation is a procedure for acquiring new learning through existing information utilizing fuzzy rationale [10],[11]. The working of the fuzzy system is based upon the 25 rule-based with 5- membership function, where two input signal fuzzification is done as shown below [20]-[23]. The single output is defuzzified by using the weighted average method and implemented in each area of the simulated power system.

Table1: Fuzzy Logic Rule Base

\begin{tabular}{|c|c|c|c|c|c|c|}
\hline \multicolumn{7}{|c|}{ Change in Error $\left(e^{*}\right)$} \\
\hline \multirow{6}{*}{ 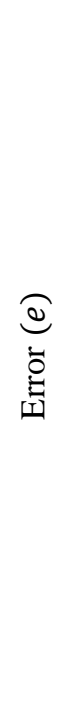 } & & $\begin{array}{l}\text { in } 2 \mathrm{mf} \\
2\end{array}$ & $\begin{array}{l}\text { in } 2 m f \\
2\end{array}$ & $\begin{array}{l}\text { in } 2 m f \\
3\end{array}$ & $\begin{array}{l}\text { in } 2 \mathrm{mf} \\
4\end{array}$ & $\begin{array}{l}\text { in } 2 \mathrm{mf} \\
5\end{array}$ \\
\hline & $\begin{array}{l}\text { in1m } \\
\text { f1 }\end{array}$ & $\begin{array}{l}\text { outmf } \\
1\end{array}$ & $\begin{array}{l}\text { outmf } \\
2\end{array}$ & $\begin{array}{l}\text { outmf } \\
3\end{array}$ & $\begin{array}{l}\text { outmf } \\
4\end{array}$ & $\begin{array}{l}\text { outmf } \\
5\end{array}$ \\
\hline & $\begin{array}{l}\text { in1m } \\
\text { f2 }\end{array}$ & $\begin{array}{l}\text { outmf } \\
6\end{array}$ & $\begin{array}{l}\text { outmf } \\
7\end{array}$ & $\begin{array}{l}\text { outmf } \\
8\end{array}$ & $\begin{array}{l}\text { outmf } \\
9\end{array}$ & $\begin{array}{l}\text { outmf } \\
10\end{array}$ \\
\hline & $\begin{array}{l}\text { in1m } \\
\text { f3 }\end{array}$ & $\begin{array}{l}\text { outmf } \\
11\end{array}$ & $\begin{array}{l}\text { outmf } \\
12\end{array}$ & $\begin{array}{l}\text { outmf } \\
13\end{array}$ & $\begin{array}{l}\text { outmf } \\
14\end{array}$ & $\begin{array}{l}\text { outmf } \\
15\end{array}$ \\
\hline & $\begin{array}{l}\text { in } 1 \mathrm{~m} \\
\mathrm{f} 4\end{array}$ & $\begin{array}{l}\text { outmf } \\
16\end{array}$ & $\begin{array}{l}\text { outmf } \\
17\end{array}$ & $\begin{array}{l}\text { outmf } \\
18\end{array}$ & $\begin{array}{l}\text { outmf } \\
19\end{array}$ & $\begin{array}{l}\text { outmf } \\
20\end{array}$ \\
\hline & $\begin{array}{l}\text { in } 1 \mathrm{~m} \\
\mathrm{f} 5\end{array}$ & $\begin{array}{l}\text { outmf } \\
21\end{array}$ & $\begin{array}{l}\text { outmf } \\
22\end{array}$ & $\begin{array}{l}\text { outmf } \\
23\end{array}$ & $\begin{array}{l}\text { outmg } \\
24\end{array}$ & $\begin{array}{l}\text { outmf } \\
25\end{array}$ \\
\hline
\end{tabular}

\section{State Space Equation And Model}

State space analysis is done to understand the inter-area oscillations. As the simulated system is subjected to small load disturbance, so the ability of power system to remain in synchronism against small disturbances is observed by small signal stability analysis. System instability may arise due to two reasons. Firstly, oscillatory response with high amplitude peak, after introducing disturbance and secondly due to a continuous increase in rotor angle because of insufficient synchronizing torque.

State variables of the simulated power system are, $\left[\Delta X_{E 1}, \Delta X_{E 2}, \Delta X_{E 3}, \Delta P_{G 1}, \Delta P_{G 2}, \Delta P_{G 3}, \Delta f_{1}, \Delta f_{2}, \Delta f_{3}\right.$,

$\triangle P T L 1, \triangle P T L 2, \triangle P T L 3$ represented in the canonical form [13]-[14].

Eigenvalue technique can be applied for further stability analysis. The calculation to obtain variation in frequency of three regions could be tabulated as follows;

State space model is represented in the form of $\dot{X}=A \mathrm{x}+B \mathrm{u}$.And their final state space matrix comprising of the main, control and disturbance matrices of a three-area system would be;
$\Delta f_{1}(s)=-\frac{R_{1} K_{p} m_{1}\left(s T_{g}+1\right)\left(s T_{t}+1\right)}{K_{p}\left(s+K_{i_{1}} R_{1}\right)+R_{1} s\left(s T_{g}+1\right)\left(s T_{p}+1\right)\left(s T_{t}+1\right)}$

$\Delta f_{2}(s)=-\frac{R_{2} K_{p} m_{2}\left(s T_{g}+1\right)\left(s T_{t}+1\right)}{K_{p}\left(s+K_{i_{2}} R_{2}\right)+R_{2} s\left(s T_{g}+1\right)\left(s T_{p}+1\right)\left(s T_{t}+1\right)}$

$\Delta f_{3}(s)=-\frac{R_{3} K_{p} m_{3}\left(s T_{g}+1\right)\left(s T_{t}+1\right)}{K_{p}\left(s+K_{i_{3}} R_{3}\right)+R_{3} s\left(s T_{g}+1\right)\left(s T_{p}+1\right)\left(s T_{t}+1\right)}$

On the other hand, power transfer amongst these power pools is as well given as follows;

$\Delta \mathrm{P}_{12}(\mathrm{~s})=2 \pi \mathrm{T}^{0} / \mathrm{S}\left[\Delta \mathrm{f}_{1}(\mathrm{~s})-\Delta \mathrm{f}_{2}(\mathrm{~s})\right]$
$\Delta \mathrm{P}_{13}(\mathrm{~s})=2 \pi \mathrm{T}^{0} / \mathrm{S}\left[\Delta \mathrm{f}_{1}(\mathrm{~s})-\Delta \mathrm{f}_{3}(\mathrm{~s})\right]$
$\Delta \mathrm{P}_{23}(\mathrm{~s})=2 \pi \mathrm{T}^{0} / \mathrm{S}\left[\Delta \mathrm{f}_{2}(\mathrm{~s})-\Delta \mathrm{f}_{3}(\mathrm{~s})\right]$

Furthermore, the three-area control system state space equations for Eigenvalue calculation can be developed as follows;

$$
\begin{aligned}
& \Delta \dot{X}_{E_{1}}=\frac{1}{\tau_{s g_{1}}}\left[-\Delta X_{E_{1}}+\Delta P_{C_{1}}-\Delta f_{1} / R_{1}\right] \\
& \Delta \dot{X}_{E_{2}}=\frac{1}{\tau_{s g_{2}}}\left[-\Delta X_{E_{2}}+\Delta P_{C_{2}}-\Delta f_{2} / R_{2}\right] \\
& \Delta \dot{X}_{E_{3}}=\frac{1}{\tau_{s g_{3}}}\left[-\Delta X_{E_{3}}+\Delta P_{C_{3}}-\Delta f_{3} / R_{3}\right] \\
& \Delta \dot{P}_{G_{1}}=\frac{1}{\tau_{t_{1}}}\left[-\Delta P_{G_{1}}+\Delta X_{E_{1}}\right] \\
& \Delta \dot{P}_{G_{2}}=\frac{1}{\tau_{t_{2}}}\left[-\Delta P_{G_{2}}+\Delta X_{E_{2}}\right] \\
& \Delta \dot{P}_{G_{3}}=\frac{1}{\tau_{t_{3}}}\left[-\Delta P_{G_{3}}+\Delta X_{E_{3}}\right]
\end{aligned}
$$

$$
\Delta \dot{f}_{1}=\frac{1}{\tau_{p s_{1}}}\left[-\Delta f_{1}+K_{p s_{1}} \Delta P_{G_{1}}-K_{p s_{1}} \Delta P_{D_{1}}-\right.
$$$$
\left.K_{p s 1} \Delta P_{T L_{1}}\right] . .(13)
$$

$\Delta \dot{f}_{2}=\frac{1}{\tau_{p s_{2}}}\left[-\Delta f_{2}+K_{p s_{2}} \Delta P_{G_{2}}-K_{p s_{2}} \Delta P_{D_{2}}-\right.$ Kps2APTL2]..(14)

$\Delta f_{3}=\frac{1}{\tau_{p s_{3}}}\left[-\Delta f_{3}+K_{p s_{3}} \Delta P_{G_{3}}-K_{p s_{3}} \Delta P_{D_{3}}-\right.$ Kps34PTL3]..(15)

$$
\begin{aligned}
& \Delta \dot{P_{T L_{1}}}=2 \pi T_{12}^{\circ}\left[\Delta f_{1}-\Delta f_{2}\right]+2 \pi T_{13}^{\circ}\left[\Delta f_{1}-\Delta f_{3}\right] \\
& \Delta \dot{P_{T L_{2}}}=2 \pi T_{12}^{\circ}\left[\Delta f_{1}-\Delta f_{2}\right]+2 \pi T_{23}^{\circ}\left[\Delta f_{2}-\Delta f_{3}\right] \\
& \Delta \dot{P_{T L_{3}}}=2 \pi T_{13}^{\circ}\left[\Delta f_{1}-\Delta f_{3}\right]+2 \pi T_{23}^{\circ}\left[\Delta f_{2}-\Delta f_{3}\right]
\end{aligned}
$$

Published By:

Blue Eyes Intelligence Engineering

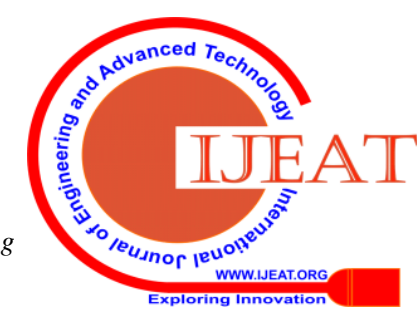




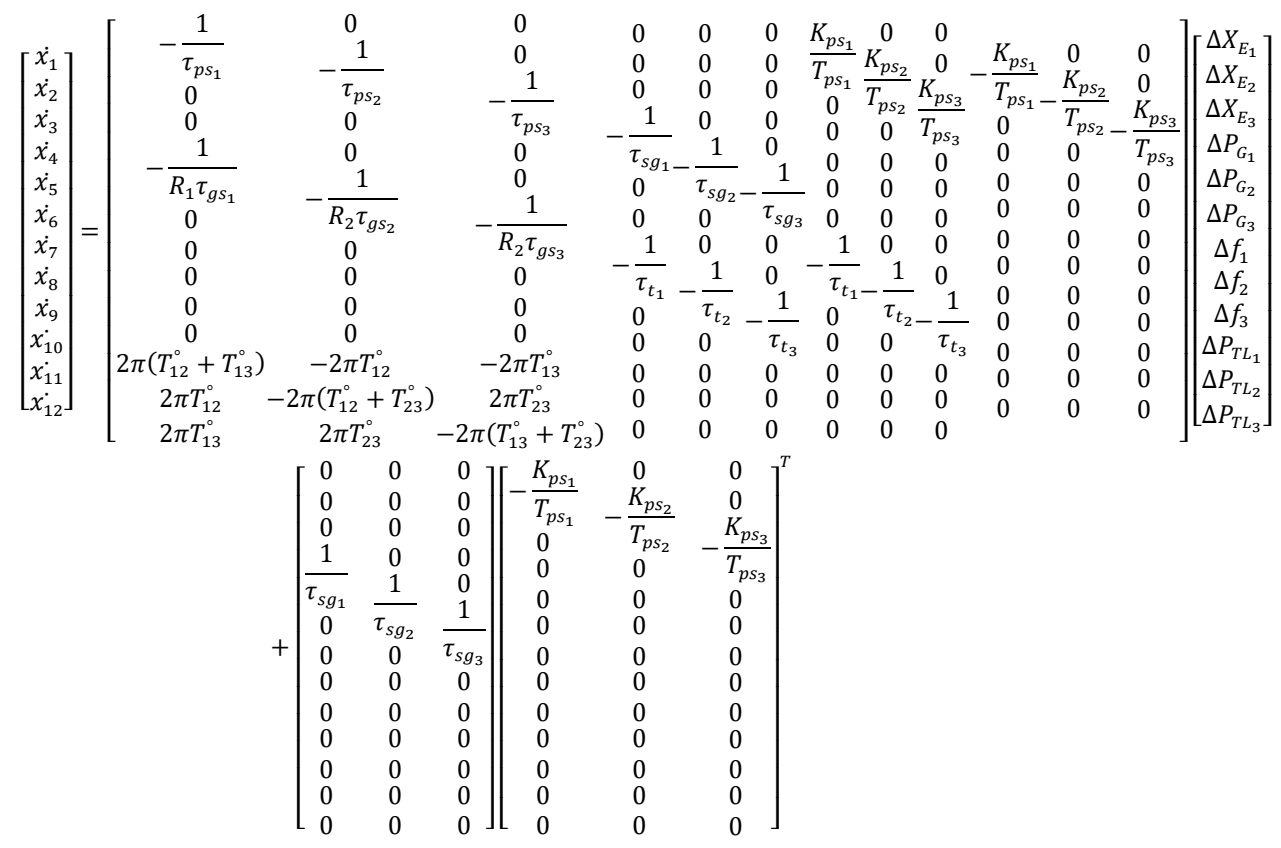

\section{Eigenvalues Analysis}

The Linearized power system shown in the matrix form can further be analyzed by eigenvalues. Arnoldi algorithm is used for computing approximations to eigenvalues of a non-Symmetric matrix constructed in a state space model, $\Delta X=[A] X$, Where $\mathrm{X}$ is a state vector and $\mathrm{A}$ is represented as a State matrix. By taking the Laplace transform of state equation, new equation in $\mathrm{s}$ domain will be $\operatorname{det}(s[I]-[A])=0$. The value of $\mathrm{s}$ that satisfies the equations is the eigenvalue of State matrix [A] [6]. For a system to be stable eigenvalues must be in lefthand side of the imaginary axis, otherwise, the system will be unstable. Eigenvalues of the simulated system are analyzed with PI and the FL implemented in the system, which shows more stability with the Fuzzy controller in the system.

\section{MODELLING AND SIMULATION}

The technique of using simulations in the monitoring, analysis and verification of the results obtained from power system is quite very effective and reliable [2]-[3]. The three-area model depicting a large power pool is simulated and the parameters chosen are illustrated below in Table II and figure 1.

Table 2: Parameters are chosen for Three Area System

\begin{tabular}{|l|l|l|l|l|l|l|l|}
\hline Name & $K_{g}$ & $T_{g}$ & $K_{\mathrm{t}}$ & $T_{\mathrm{t}}$ & $\mathrm{H}$ & $\begin{array}{l}\mathrm{D}(\mathrm{p}, \mathrm{y} . \\
\mathrm{MW} / \mathrm{Hz})\end{array}$ & $\frac{1}{R}$ \\
\hline Area 1 & 1 & 0.08 & 1 & 0.3 & 35 & 1.00 & 125 \\
\hline Area 2 & 1 & 0.08 & 1 & 0.3 & 25 & 0.60 & 10 \\
\hline Area 3 & 1 & 0.08 & 1 & 0.3 & 25 & 0.90 & 2.5 \\
\hline
\end{tabular}

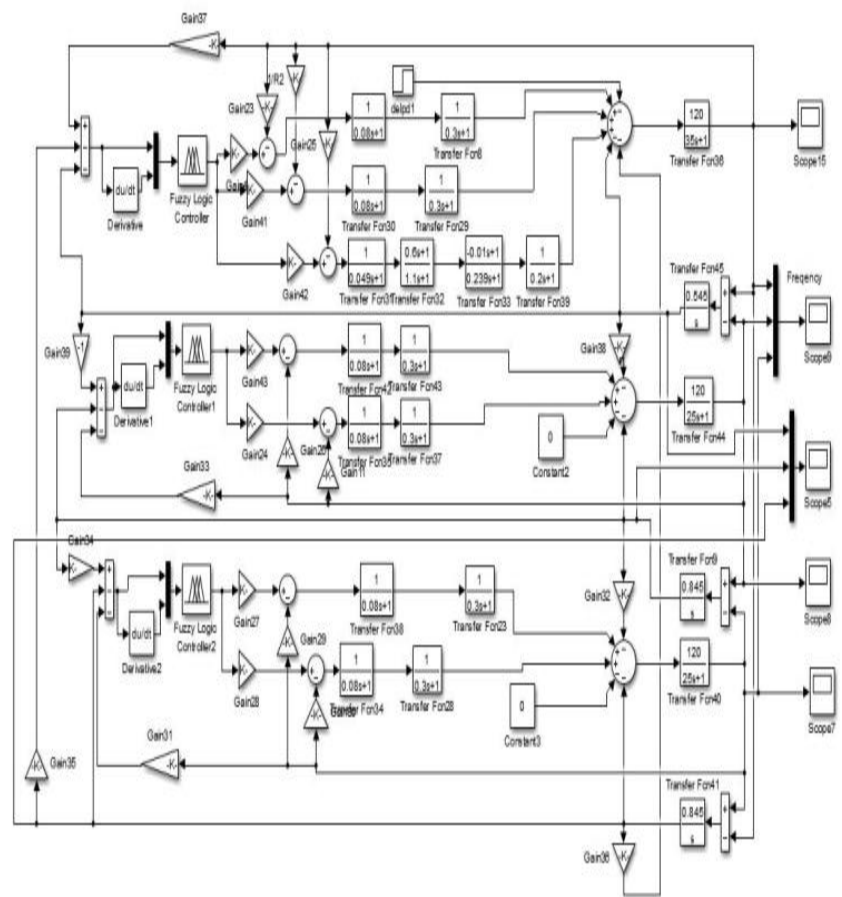

Fig.1. Simulink main model with fuzzy logic of a threearea power pool.

\section{RESULTS AND DISCUSSIONS}

As it is shown in the figure below that no error signal is generated in the power system if no controller is employed, and with PI controller, a steady error signal is generated [29]. While using the fuzzy controller in the same system error signal variation and its dynamics depicts the load variation more precisely, hence providing the better results with the proposed strategy. Moreover, in this simulation result we are able to see that when it comes to power pools which are connected together,

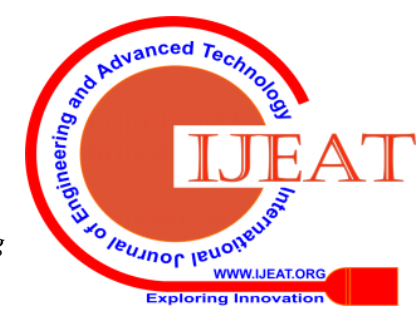




\section{Small Signal Stability Analysis of Multi-Area Power System}

due to constant and abrupt fluctuations in the power output, there will be corresponding deviations from their standard values for both frequencies as well as tie-line power passing through these interconnectors.

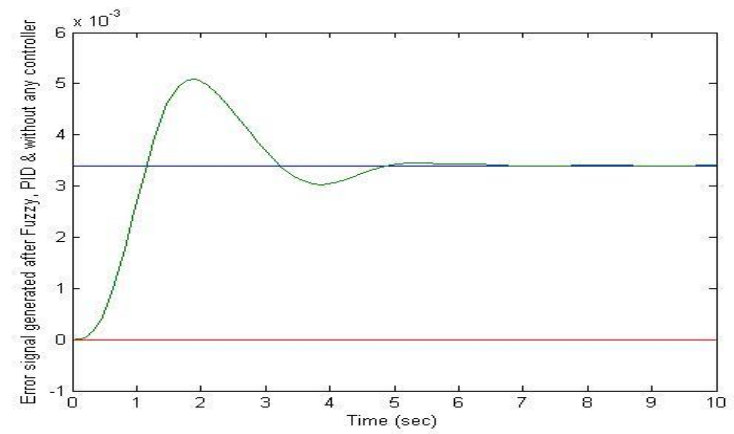

Fig.2. The Error signal generated without a controller, PI and fuzzy controller.

Implementation of the power frequency regulation is there to ensure that frequency deviations from their acceptable limits are minimized during the slow developing faults or disturbances, and to regulate the exchange of power in these power pools. On the other hand, the application of the electromechanical regulators is so as to bring the response to a steady state in the shortest possible time due to their instantaneous action because of the proportional regulator incorporated in them. This proportional component of the regulator is responsible for the generation of a regulating signal which would be corresponding to the deviation response or error of the power transmission network. It would, therefore, be observed that selection of the right value of $K_{p}$ in terms of the design of controllers is of great importance in as far as reduction of the steady state error in the controllers may be concerned, and at the same time with increased values of $K_{p}$ could necessity a reduction in the time constant as well as damping [16].

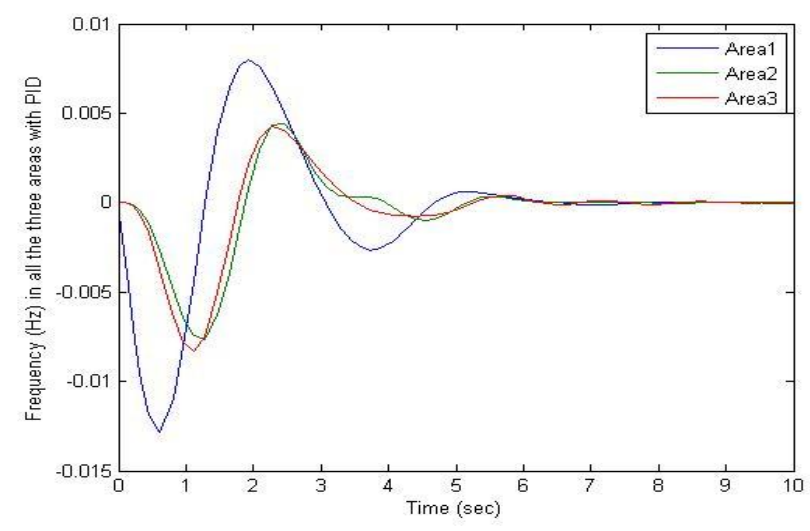

Fig.3. Frequency variation of three areas with PI controller during transients

Frequency variation in all the three areas was analyzed using the simulation process and where it was observed that the system response had to come to a steady state condition after the generation of oscillations by using different controllers. Their oscillations are finally reaching to steady state values because of damping provided by PI controller [18]. By using PI controller system stability and performance has increased without increasing the steady state error.

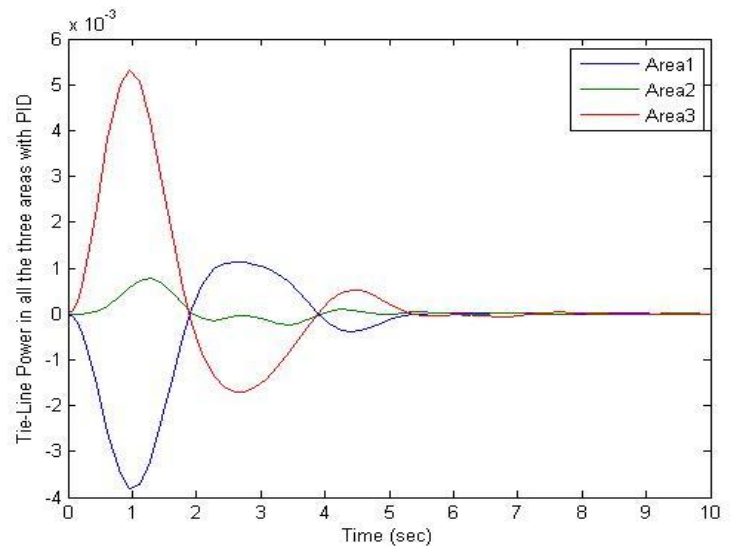

Fig. 4. Tie-line power of three areas with PI controller during transients.

The tie-line power variations of all the three areas is shown in figure 4. After providing the load variation in one area, other two areas would as well continue to face variation in their behaviour while they try to settle down after the occurrence of transients. In this regard, PI controllers would then be employed so as to make system response stable and sustainable during dynamic conditions.

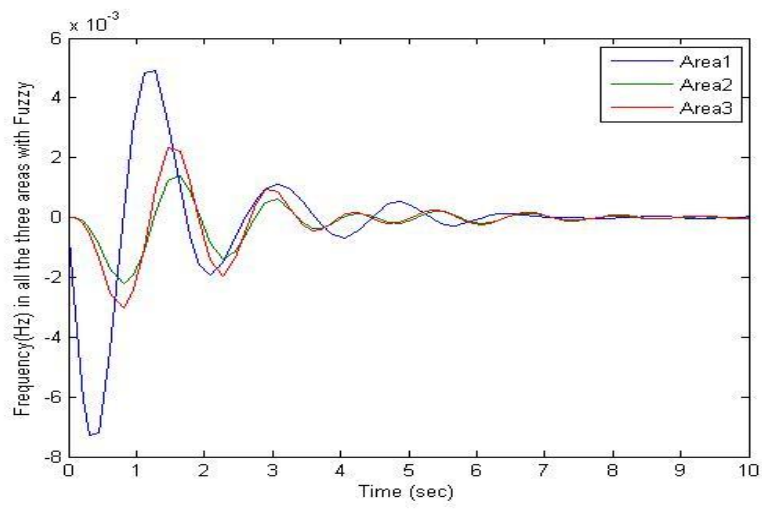

Fig. 5. Frequency variation of three areas with fuzzy controller during transients.

In this simulation result we are able to see that when it comes to power pools which are connected together, due to constant and abrupt fluctuations in the power output, in this case taking into consideration the rapid and spontaneous small variations in the load of the three-area control system, there will be a corresponding deviation from their standard values for both frequency as well as tie-line power passing through these interconnectors [23]. Implementation of the power frequency regulation is there to ensure that frequency deviation is maintained within acceptable limits during the slow developing faults or disturbances, and to regulate the exchange of power in these power pools. And therefore, for optimization purposes, a fuzzy logic was employed. Small Signal Stability analysis can be done by using Eigenvalues. An Eigenvalue analysis of the system does provide with a better understanding of small signal stability like rotor angle variation [22],[24], Tie-Line power control and system behaviour under transient's conditions in terms of state variables [13]. The below-mentioned values describe the System stability of simulated three area system with and without controllers [5].

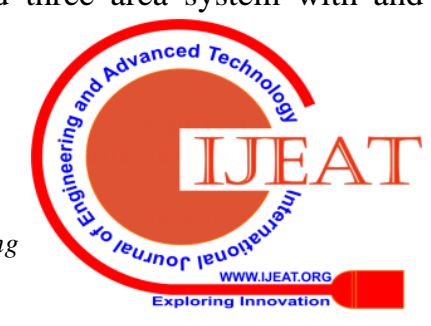


Table 3: Eigenvalue Analysis with and without controllers

\begin{tabular}{|c|c|c|c|}
\hline $\begin{array}{l}\text { State } \\
\text { Space } \\
\text { Variables }\end{array}$ & $\begin{array}{l}\text { Eigenvalues } \\
\text { without } \\
\text { Controller }\end{array}$ & $\begin{array}{l}\text { Eigenxalues with } \\
\text { PI Controller }\end{array}$ & $\begin{array}{l}\text { Eigenxalues } \\
\text { with Fuzzy } \\
\text { Controller }\end{array}$ \\
\hline$\Delta \dot{X}_{E_{1}}=x_{2}$ & $20.2274+30.6655 i$ & $-0.1474-7.377 i$ & $-0.1489+6.6025 i$ \\
\hline$\Delta X_{x_{2}}=x_{2}$ & $20.2274-30.6655 i$ & $-0.1474-7.377 \mathrm{i}$ & $-0.1489-6.6025 i$ \\
\hline$\Delta X_{x_{2}}=x_{z}$ & -36.2542 & $-0.6165-6.783 i$ & $-0.3035-6.0333 i$ \\
\hline$\Delta \dot{P}_{c_{4}}=x_{4}$ & $6.8842+3.6386 i$ & $-0.6165-6.7835 i$ & $-0.3035-6.0333 i$ \\
\hline$\Delta \dot{P}_{c_{2}}=x_{3}$ & $6.8842-3.6386 \mathrm{i}$ & -6.7539 & -5.3006 \\
\hline$\Delta \dot{P}_{c_{2}}=x_{0}$ & $5.9109+1.9387 i$ & -5.4887 & -3.1697 \\
\hline$\Delta f_{2}=x$ & $6.8842-3.6386 i$ & -5.1718 & $-0.6831-1.8696 \mathrm{i}$ \\
\hline$\Delta f_{z}=\dot{x}_{z}$ & -9.1822 & -3.7926 & $-0.6831-1.8696 \mathrm{i}$ \\
\hline$\dot{\Delta f_{z}}=\dot{x}_{0}$ & -7.4895 & $-1.7699+0.975 i$ & -1.5402 \\
\hline$\Delta \dot{P}_{\mathrm{TL}}=\dot{x}_{10}$ & -1.7744 & $-1.7699-0.975 i$ & -1.3581 \\
\hline$\Delta \dot{P}_{T_{1}}=\dot{x}_{12}$ & -3.9165 & -1.1551 & -1.6058 \\
\hline$\Delta \dot{P}_{\mathrm{TL}}=\dot{x}_{12}$ & 0.0000 & 0.0000 & 0.0000 \\
\hline
\end{tabular}

By comparing the Eigenvalue of a state variable in case of uncontrolled, PID and fuzzy controller system state, behavioural analysis can be done. It has been analyzed that by using different controllers the Eigenvalues started having more negative real part compared to without controller and values become more negative when the fuzzy controller is being employed. In the Multi-Area system, the behaviour of tie-line power and frequency are important to analyze and after using fuzzy controller stability and damping of oscillations have become fast and overall response of system has improved [17], [21].

\section{CONCLUSION AND FUTURE WORK}

This research work has mainly investigated on oscillatory nature of Multi-Area system during load disturbance, at the same time providing a comparative solution between PI and Fuzzy logic controller. Small Signal Stability analysis with Eigenvalues is also done to validate the results. With the help of Fuzzy controller, The system has shown better stability and rigidness in terms of frequency and Tie-Line Power Oscillations [20]. Small signal stability analysis of system shows Fuzzy controller will act better against PI controller as far as disturbance is small in nature like load change and slow acting faults.

For the Future improvement, we intend to possibly introduce other optimization techniques such as Genetic Algorithm (GA) or Bacteria Foraging Optimization Algorithm (BFOA) program so that they can help in speeding up the entire process and to change the values of the various parameters present in the power system under investigation [25], [26] and which can be used in coming up with the changes in the load demand. This, therefore, will go a long way in terms of contributing to a reduction in the changes in the frequency and a further reduction to the TieLine power and thereby help in maintaining the stability of the system. We may also want to incorporate a programming technique and make comparisons of the values obtained and those with the reference. It is also seen that BFOA technique has quicker convergence characteristics [28]. Most of these optimization techniques serve to be quite useful for obtaining the optimized values of the various parameters as compared to the general hit and trial technique which is extremely tedious and time taking method.

\section{REFERENCES}

1. A.M.G. Cornelissen, J. van den Berg, W.J.Koops, M. Grossman, H.M.J. Udo," Assessment of the contribution of sustainability indicators to sustainable development: A novel approach using fuzzy set theory", Agr. Eco. Env. 2001, 8, 173-185.

2. Adil Usman, BP Divakar "Simulation study of load frequency control of single and two area systems". IEEE Global Humanitarian Technology Conference, pp.214-219, 2012.

3. B. Öztaysi, H. Behret, Ö. Kabak, I. Uçal Sarı, C. Kahraman, "Fuzzy inference systems for disaster response", In Decision Aid Models for Disaster Management and Emergencies. Atlantis Computational Intelligence Systems, vol 7. Atlantis Press, Paris.

4. Bezdek, J.C.," Fuzzy models-What are they, and why?", IEEE Trans. Fuzzy Sys.1993, 1, 1-6.

5. C.P.Pappis, C.I. Siettos (2005)," Fuzzy Reasoning. In", Burke E.K., Kendall G. (eds) Search Methodologies. Springer, Boston, MA

6. Chunyu Chen, Kaifeng Zhang, Kun Yuan, Zonghe Gao, XianliangTeng, Qia Ding," Disturbance Rejection based LFC for Multi-Area parallel Interconnected AC/DC System”, IET Generation, Transmission \& Distribution, Vol. 10, Issue 16, 128 2016.

7. CIGRE Task Force 38.01.07 on Power System Oscillations, "Analysis and control of power system oscillations," CIGRE Technical Brochure, no. 111, Dec. 1996.

8. D.G. Padhan, S.Majhi, "A new control scheme for PID load frequency controller of single area and multi-area power systems", ISA Transactions, vol.52, pp.242-251, 2013.

9. DipayanGuha, Provas Kumar, SubrataBanerjee,’Load Frequency control of Large-scale Power System using Quasi-Oppositional Grey Wolf Optimization Algorithm", Int. J.Electr. Power Energy System, 19(2016) pp.1693-1713.

10. G.J. Klir, B. Yuan, " FuzzySets and Fuzzy Logic-Theory and Applications", Prentice Hall: Upper Saddle River, NJ, USA, 1995.

11. H. Yousef," Adaptive fuzzy logic load frequency control of multiarea power system" Int. J. Elect. Power Syst. Res., 68 (2015), pp. 384-395

12. H.Bevrani, Y.Mitani and K.Tsuji, "Robust decentralized load frequency control using an iterative linear matrix inequalities algorithm”, IEE Pro. Gener. Transm. Distrib., vol.151, no.3, pp.347354, 2004.

13. I. Erlich, A. Fischer,"Fast Assessment of Small-Signal Oscillatory Stability in Large Interconnected Power Systems", IEEE Conference, BPC proceedings, vol. 2, 2002

14. I. J Nagrath and D. P Kothari," Modern power system analysis", TMH 1993.

15. IEEE PES Working Group on System Oscillations, "Power System Oscillations,’IEEE Special Publication 95-TP-101, 1995

16. K.Tanaka, "An Introduction to Fuzzy Logic for Practical Applications”, Springer-Verlag., New York, NY, USA, 1991.

17. LC Saikia "Automatic Generation Control of a combined cycle gas turbine plant with classical controllers using firefly algorithm", International Journal of Electrical Power and Energy Systems, vol.53, pp. 27-33, 2013

18. OlafRuhle," Eigenvalue Analysis - All Information on Power System Oscillation Behavior Rapidly Analyzed", Senior Consultant, Newsletter Issue 99 under Siemens PTI, Sep. 2006

19. Olle L. Elgerd,"Electric energy systems theory-an introduction", $2^{\text {nd }}$ edition.Tata McGraw-Hill:2000

20. Olle L. Elgerd. C.Fosha,'Optimal megawatt frequency control of multi-area electric energy systems", IEEE Trans Electric Power Apparatus System, vol.PAS-89, pp.556-63, 1970 
Small Signal Stability Analysis of Multi-Area Power System

21. P. Kundur, F. Howell, L. Wang, "A Tool For Small-Signal Security Assessment of Power Systems", in Proc. 2001 Power Industry Computer Applications Conf., pp. 312-323

22. P. Kundur, G. J. Rogers, D. Y. Wong, "A comprehensive Program Package for Small Signal Stability Analysis of Power Systems", IEEE Trans. on Power Systems, vol. 5

23. P.Kundur, "Power System Stability and Control", New York, McGraw-Hill, 1994

24. Ravi Shankar, Ravi Bhushan, Kalyan Chatterjee," Small Signal stability analysis for two area interconnected power system with load frequency controller in coordination with FACTS and energy storage devices", Ain Shams Engineering Journal, Vol, 7, pp 603-612,2016

25. S. Prakash, S.K. Sinha," Neuro-Fuzzy computational technique to control load frequency in hydro-thermal interconnected power system”, J. Inst. Eng. India Ser. B, 96(3) (2015), pp. 273-282

26. S.B. Shyree, N. Kamaraj,"Hybrid Neuro-Fuzzy approach for automatic generation control in restructured power system", Int. J. Electr. Power Energy Syst., 74 (2016), pp. 274-285

27. T. Takagi, M. Sugeno,"Fuzzy identification of systems and its applications to modelling and control", IEEE Trans. Sys. Man. Cybern.1985, 15,

28. U.K.Rout, R.K.Sahu, S.Panda, "Design and analysis of differential evolution algorithm based automatic generation control for interconnected power system", Ain Shams Engineering Journal, vol. 4, No. 3, pp. 409, 2013

29. Wen Tan, "Unified tuning of PID load frequency controller for power systems via IMC", IEEE Transactions on Power Systems, vol.25, no.1, pp.341-350, 2010

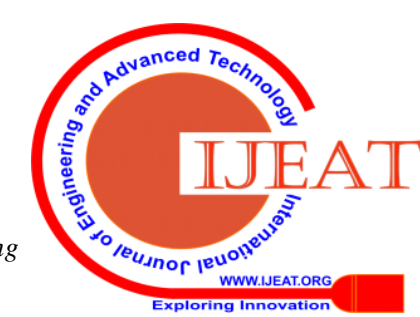

